\title{
Investigating the Knowledge, Attitudes, Practices and Perceived Barriers of Breast Feeding among Saudi Women in the National Guard Hospital Jeddah
}

\author{
By Abeer Orabi* \\ Razan al-Sayad" \\ Kholoud Alharthi
}

\begin{abstract}
A descriptive correlational cross-sectional design was used to collect data from a convenient sample of 100 Saudi women. The study participants were recruited from Ward. Women were interviewed face to face. Data was collected by using a five sections structured questionnaire: Socio-demographic background; breastfeeding knowledge; perceived barriers and practice; and an Iowa Infant Feeding Attitude Scale (IIFAS). Two thirds of the participants (62\%) had a good knowledge regarding breastfeeding health benefits. However, the minority of them (10\%) had a positive attitude toward breastfeeding. The most commonly reported barriers were insuffient milk supply and lack of knowledge (82\%). A statistically significant correlation was found between breastfeeding knowledge and maternal age $(r=0.22)$, also there was a good significant correlation between women's knowledge and their attitude $(r=0.60)$ toward breastfeeding. Although Saudi women have good knowledge regarding breastfeeding importance, they have a neutral attitude toward it and several barriers might prevent them from its practice.
\end{abstract}

Keywords: Attitudes, Breastfeeding knowledge, Perceived barriers

\section{Introduction}

Breastfeeding is the normal way of giving infants the needed nutrients for proper growth. A wide range of breastfeeding's benefits for mother, child and family are well known and documented in many perspectives as socio-economic and psychological. Furthermore, it is well known that, these benefits can be either immediate or long-term. To promote breastfeeding and ensure that adequate counselling and support are provided to initiate and maintain optimal breastfeeding practices, UNICEF and WHO started the Baby Friendly Initiative (BFI) in 1991 and required 10 steps for hospital accreditation as baby friendly, and now there are 152 baby friendly hospitals ${ }^{1}$.

Exclusive breastfeeding during the first six months of life and then continuation while adding complementary feeding up to two years was and still is recommended by $\mathrm{WHO}^{2}$, $\mathrm{UNICEF}^{1}$ and the American Academy of Paediatrics

\footnotetext{
* Assistant Professor, College of Nursing, King Saud Bin Abdul Aziz University, Saudi Arabia \& Lecturer, College of Nursing, Cairo University, Egypt.

${ }^{\dagger}$ Graduate Student, College of Nursing, King Saud Bin Abdul Aziz University, Saudi Arabia.

* Graduate Student, College of Nursing, King Saud Bin Abdul Aziz University,Saudi Arabia.

1 UNICEF. The Baby Friendly Hospital Initiative. Retrieved from http://www.unicef.org. [Accessed: 31 October 2015]

${ }^{2}$ WHO. 10 Facts on Braestfeeding. Retrieved from http://www.who.int. [Accessed: 31 May 2015]
} 
(AAP 2012), and supported in many recent systematic reviews for healthy growth and development and proper digestion of the infant (Kramer and Kukuma 2012) in addition to protection from respiratory infections and diarrhoeal disease. Also it is used to treat obesity and certain non-communicable diseases including asthma, diabetes and heart diseases later in life (Horta and Victoram 2013). Moreover it helps with the improvement of academic achievement (Oddy et al. 2011) and reduces the risk of childhood leukaemia (Amitay and Boker 2015). Also, it fosters the process of attachment between mother and baby leading to a sense of wellbeing and security ${ }^{2}$. Longer breastfeeding duration improves bone strength (Chapman 2012), and decreases risk of breast and ovarian cancer (Nagata et al. 2012, Collaborative Group on Hormonal Factors in Breast Cancer 2002), postpartum haemorrhage (Sobhy 2004) and some cardiovascular diseases for the mother (Labbok 2001). Initiating breastfeeding in the first hour of life decreases the risk of neonatal death by $20 \%$. Society also benefits by decreasing medical costs as sick care visits, prescriptions and hospitalizations (Debes et al. 2013).

Inspite of having all these benefits only $38 \%$ of infants globally are exclusively breastfed. At the same context, recent analyses indicate that, suboptimal breastfeeding practices in terms of initiation, exclusivity and duration contribute to over 800,000 deaths $(11.6 \%)$ in children under five years of age. Accordingly, following the international organizations' recommendations would decrease children morbidity and mortality (Black et al. 2013). Actually, breastfeeding is feasible if women are well informed and supported. Additionally, breastfeeding is a natural practice and a learned behavior ${ }^{3}$.

Regionally, percentages of infants who are breastfed within one hour and had exclusive breastfeeding in the first six months were $42 \%$ and $49 \%$ respectively in South Asia ${ }^{4}$. Because of these suboptimal breastfeeding practices, increasing the percent of exclusive breastfeeding reaching $50 \%$ is the fifth global nutrition target for 2025 set by the World Health Assembly Resolution 65.6 in 2012 . In consequence, WHO and UNICEF recommended some actions at the health system, community and policy maker's level that will help to achieve this goal ${ }^{6}$.

Concerning the compliance with WHO recommendation in Saudi Arabia, a nationwide survey reported that, bottle feeding was introduced by one month of age to $51.4 \%$ of the participants' infants and to $90 \%$ by six months of age (El Mouzan et al. 2009). Recently, the Saudi Arabian Ministry of Health announced

${ }^{1}$ UNICEF. Nutrition, Braestfeeding. Retrieved from http://www.unicef.org. [Accessed: 20 April 2015]

${ }_{2}^{2}$ UNICEF. The Baby Friendly Hospital Initiative. Retrieved from http://www.unicef.org. [Accessed: 31 October 2015]

${ }^{3}$ WHO. Breastfeeding. Retrieved from www.who.int $>$ topics $>$ breastfeeding. [Accessed: 20 July 2015], UNICEF. Nutrition/Breastfeeding. Retrieved from www.unicef.org. [Accessed: 21 July 2015]

${ }^{4}$ UNICEF. A Post-2015 World Fit for Children Issue Brief: Breastfeeding. Retrieved from goo.gl/nhla1i. [Accessed: 1 November 2015]

${ }_{5}^{5}$ Resolution WHA 65.6.2012. Comprehensive Implementation on Maternal, Infant and Young Child Nutrition. In: Sixty-fifth World Health Assembly Geneva. Resolutions and decisions, Annexes: WHO. Retrieved from goo.gl/CvCjaA.

6 WHO Global Nutrition Targets 2025. Breastfeeding Policy Brief. Retrieved from http://www.who.int. [Accessed: 1 July 2015] 
after conducting nutritional survey in five regions that, the rate of breastfeeding in the first six months of child's age reached $35.1 \%$, while, $99 \%$ of pregnant women are educated on the benefits of breastfeeding ${ }^{1}$. Additionally, the mean duration of breastfeeding has decreased from 13.4 months in 1987 to 8.5 months in 2010 (AlJuaid et al. 2014). For initiation of breastfeeding within one hour after birth, a study conducted in the Al-Hassa Province reported that about $11.4 \%$ of the participants given timely initiation (El-Gilany et al. 2012).

Referring to the perceived barriers of breastfeeding, it was reported that, working, low income, pushing formula into hospital and heavy formula advertisements can limit the breastfeeding practices (Rani 2014) in addition to, lack of information, fear of pain, misconceptions, worries about breastfeeding in public, negative postpartum hospital experiences and lack of support after going home (Furman et al. 2013). At the national level, previous studies added insufficient milk supply, being too busy to breastfeed, change in breast shape and availability of housekeepers acted as barriers among Saudian women (Mosalli et al. 2012, Hala et al. 2013). So, it can be concluded that, the breastfeeding practices may be far from WHOs recommendations.

Although breastfeeding is a natural practice, still there are many factors negatively affecting women's attitudes toward it and a lot of barriers halting its conduction. Some mothers find it difficult to adhere to exclusive breastfeeding for six months despite the increased rate of initiation (Whalen and Cramton 2012). Further, some studies conducted in Saudi Arabia revealed that, the percent of exclusive breastfeeding was low Inspite of having a high level of education. Also, mixed feeding was the common way of feeding. Additionally, reasons for discontinuing breastfeeding were individualized as sickness of mother or baby, use of contraception or taking drugs (Alwelaie et al. 2010). At the same time, some factors remain inconclusive and not well clarified in detail so, additional examination is of concern. Furthermore, updated assessment and clear description of breastfeeding indicators are important to plan and carryout tailored enhancement programs that suit the nature of the population in relation to common and unique culture and environment.

Additionally, it was observed in a clinical training setting that many delivered women refuse to breastfeed their babies or ask nurses to put them in the nursery. In addition to, the complaints of the health care providers regarding mother's refusal to breastfeed their babies. So, all the above mentioned factors encouraged the researchers to conduct the current study to examine some modifiable variables and explore their relationship with breastfeeding attitudes. In addition to identifying why some women may be aware of the benefits of breastfeeding but have a negative attitude toward it.

Finally, it is expected that, understanding reasons limiting breastfeeding practice can help nurse to develop effective strategies helping to promote and encourage breastfeeding practice and reach the Fifth Global Nutrition Target. Especially because, the leading health organizations emphasize that countries at or

\footnotetext{
${ }^{1}$ Ministry of Health Portal. Kingdom of Saudi Arabia. 2014. Dr. Al-Qsami Calls for Developing a Strategy for the Breastfeeding Promoting Program. Retrieved from goo.gl/ aj5GsV.
} 
near $50 \%$ exclusive breastfeeding should continue to strive for improvement ${ }^{1}$. Accordingly, the aim of the current study is to assess breastfeeding knowledge, attitudes, practices and perceived barriers to breastfeeding among Saudi Arabian women in a military hospital in Jeddah.

\section{Materials and Methods}

Aim

Investigating breastfeeding knowledge, attitudes, practices and perceived barriers among Saudi women in the National Guard Hospital in Jeddah.

\section{Specific Objectives}

- To investigate the knowledge level of women about benefits of breastfeeding.

- To explore the woman's perceived barriers to breastfeeding.

- To examine the woman's attitudes toward breastfeeding.

- To assess the practice of breastfeeding in previous and present delivery.

- To correlate women's breastfeeding knowledge, attitudes and perceived barriers to their socio-demographic background.

\section{Questions}

- What is the women's knowledge level about the benefits of breastfeeding?

- What are the women's perceived breastfeeding barriers?

- What are the women's attitudes toward breastfeeding?

- How did the women practice breastfeeding?

- Is there a correlation between breastfeeding knowledge, attitudes, perceived barriers and socio-demographic back ground?

Study Design

A descriptive correlational cross-sectional design was adapted for the current study as it fits its nature.

\section{Study Area/Setting}

Data was collected at King Khalid Hospital in National Guard, Ward 2 . $\mathrm{Ward}_{2}$ is a postnatal ward where about 3,000 women are admitted annually after their vaginal or caesarean births ${ }^{2}$.

Study Subjects/Sample Size/Sampling Technique

\footnotetext{
${ }^{1}$ WHO Global Nutrition Targets 2025. Breastfeeding Policy Brief. Retrieved from http://www. who.int. [Accessed: 1 July 2015]

${ }^{2}$ King Khalid Hospital Statistics, Labor and Delivery Unit. 2014. Retrieved from Labor and Delivery Unit, electronic filing system.
} 
One hundred women were recruited in convenience and interviewed face to face after their deliveries using structured questionnaire. Women who were most readily accessible and willing to participate, primiparous and multiparous Saudian women were included in the study. While, women who had multiple pregnancies, any postpartum complication, stillbirth or infants with congenital anomalies or their babies admitted to NICU were excluded. 


\section{Data Collection Methods, Instruments Used, Measurements}

An English questionnaire encompasses five sections and is composed of 75 items was translated into Arabic and reviewed by a panel of experts in the nursing field as paediatric, community health, management and medical surgical nursing and necessary changes were done. Then the questionnaire was completed by the researchers while interviewing the participants. Four sections were designed by the researchers after an extensive literature review (Hala et al. 2013, El-Gilany et al. 2012, Alfaleh 2014, Cara et al. 2014) to elicit information on: socio-demographic background as age, education, residence, income, employment, etc.; breastfeeding knowledge; perceived barriers and practice. The fifth section is the Iowa Infant Feeding Attitude Scale (IIFAS) (De La Mora et al. 1999). The IIFAS was developed to assess maternal attitude toward infant feeding as a predictor for feeding method choice (Scott et al. 2006, Dungy et al. 1994). Studies using the IIFAS reported adequate prediction validity and internal consistency with the Cronbach's alpha 0.89 (Dungy et al. 2008).

Some items are reversely scored due to being scientifically wrong. Women were interviewed after at least 24 hours from their delivery to be able to respond and to be accessed before discharge (the average stay in $\mathrm{Ward}_{2}$ is 3-4 days). Validity of the questionnaire is confirmed by a panel of nursing experts in paediatrics, community health and research who assessed its relevancy and appropriateness to the current study aims. Necessary changes were done by the consulting Jury as adding negative family attitude as a barrier for breast feeding, and questions about digestion and constipation in the part of breast feeding benefits. In addition to using no education instead of illiterate regarding the educational level and IIFAS as a valid and reliable tool to assess attitudes toward breastfeeding. A pilot study was conducted by interviewing 10 women (10\% of the participants) who met the inclusion criteria to assess the clarity of the questionnaire items and feasibility of the study, no modifications were done. Respondents who were interviewed for piloting were part of the whole study participants.

\section{Data Management and Analysis Plan}

Data was coded, entered and analysed using the Statistical Package for Social Sciences (SPSS) version 22 for Windows. The data was presented using descriptive statistics that include frequencies, percent, means and standard deviations. Also, inferential statistics were used to examine the significance of comparison and correlation between the study variables. A p $<0.05$ is used as a significance level.

\section{Ethical Considerations}

The study was conducted after being reviewed and approved by the College of Nursing Research Committee, the Institutional Review Board (IRB) at King Khalid Hospital and King Abdullah International Medical Research Centre (KAIMRC), Jeddah, KSA. Then the researchers explained the aim and nature of the study for each woman that met the criteria for inclusion to gain her oral and written consent to participate in the current study. Written consent was obtained from non-educated 
women through their husbands. Also, the researchers emphasized that participation in the study is voluntary and confidentiality was maintained.

\section{Limitations}

A small sample size and number of settings were from the major study limitations that may restrict the generalisation of the study findings.

\section{Findings/Results}

One hundred women participated in the current study, their age ranged between 17 and 52 years with a mean of $(28.2 \pm 6.6)$ and $(83 \%)$ of them were highly educated. Majority of the participants were housewives (78\%) and (34\%) of them had a house keeper (Table 1).

Table 1. Distribution of the Socio-demographic Characteristics of the Participants

\begin{tabular}{|l|c|}
\hline \multicolumn{1}{|c|}{ Item } & Percent (n=100) \\
\hline Age (years) & 6 \\
$\bullet \leq 20$ & 64 \\
$\bullet 21-30$ & 26 \\
$\bullet 31-40$ & 3 \\
$\bullet 41-50$ & 1 \\
$\bullet \geq 51$ & $28.2 \pm 6.6$ \\
Mean \pm SD & \\
\hline Education & 14 \\
$\bullet$ Low education (Primary and preparatory education) & 83 \\
$\bullet$ High education (Secondary and university education) & 3 \\
$\bullet$ No education & \\
\hline Marital status & 100 \\
$\bullet$ Married & 100 \\
\hline Residence & 26 \\
$\bullet$ In Jeddah & 51 \\
\hline Income & 23 \\
$\bullet<5000$ SR & \\
$\bullet$ 5000-10000 SR & 78 \\
$\bullet>10000$ SR & 22 \\
\hline Employment & \\
$\bullet$ Housewife & 8 \\
$\bullet$ Employed & 14 \\
\hline Type of employment & 34 \\
$\bullet$ Health related & 66 \\
$\bullet$ Not health related & \\
\hline Housekeeper availability & \\
$\bullet$ Yes & \\
$\bullet$ No & \\
\hline
\end{tabular}

In reference to these findings, it was expected that participants had enough knowledge and time for breastfeeding their babies. Regarding to the medical and 
obstetrical history of the participants, $(69 \%)$ of them was medically free, and (72\%) multiparous (Table 2). It can be understood that, most of the participants were physically able to breastfeed in addition to having previous experience. 
Table 2. Distribution of the Participants by their Medical and Obstetrical History

\begin{tabular}{|c|c|}
\hline Item & Percent $(n=100)$ \\
\hline $\begin{array}{l}\text { Medical disorder } \\
\text { - No } \\
\text { - Cardiac } \\
\text { - Diabetes } \\
\text { - Renal } \\
\text { - Asthma } \\
\text { - Hypertension } \\
\text { - Others } \\
\end{array}$ & $\begin{array}{c}69 \\
2 \\
11 \\
2 \\
5 \\
1 \\
10\end{array}$ \\
\hline $\begin{array}{l}\text { Parity } \\
\text { - Primiparous } \\
\text { - Multiparous }\end{array}$ & $\begin{array}{l}28 \\
72\end{array}$ \\
\hline $\begin{array}{l}\text { Number of children } \\
\quad \bullet 1-5 \\
\bullet 6-10\end{array}$ & $\begin{array}{c}95 \\
5\end{array}$ \\
\hline $\begin{array}{l}\text { Status of current pregnancy } \\
\quad \text { - Planned } \\
\text { - Unplanned }\end{array}$ & $\begin{array}{l}35 \\
65\end{array}$ \\
\hline $\begin{array}{l}\text { Antenatal care during present pregnancy } \\
\quad-\text { Yes } \\
\quad-\text { No }\end{array}$ & $\begin{array}{l}79 \\
21\end{array}$ \\
\hline $\begin{array}{l}\text { Complications during present pregnancy } \\
\text { - No } \\
\text { - Pregnancy induced hypertension } \\
\text { - Gestational diabetes } \\
\text { - Premature rupture of membranes } \\
\text { - Antepartum hemorrhage } \\
\text { - Others }\end{array}$ & $\begin{array}{c}60 \\
3 \\
22 \\
2 \\
7 \\
6\end{array}$ \\
\hline $\begin{array}{l}\text { Mode of present delivery } \\
\text { - Normal vaginal delivery } \\
\text { - Assisted vaginal delivery } \\
\text { - Cesarean section }\end{array}$ & $\begin{array}{l}29 \\
31 \\
40\end{array}$ \\
\hline $\begin{array}{l}\text { Use of epidural during present delivery } \\
\quad \text { - Yes } \\
- \text { No }\end{array}$ & $\begin{array}{l}53 \\
47\end{array}$ \\
\hline $\begin{array}{l}\text { Gestational age at present pregnancy } \\
\quad \bullet<37 \text { weeks } \\
\bullet \geq 37 \text { weeks }\end{array}$ & $\begin{array}{l}46 \\
54\end{array}$ \\
\hline $\begin{array}{l}\text { Occurrence of complications during present delivery } \\
\text { - No } \\
\text { - Prolonged labor } \\
\text { - Tears or lacerations } \\
\text { - Others }\end{array}$ & $\begin{array}{c}68 \\
16 \\
6 \\
11\end{array}$ \\
\hline
\end{tabular}

Almost half of the participants (56\%) had breastfeeding education during current pregnancy and half of the educated participants (28\%) had their education by nurses during antenatal or postnatal period (Table 3). All of them 
should be educated regarding breastfeeding with the nurse playing a more crucial role as a health educator. Two thirds of the participants $(62 \%)$ had a good knowledge regarding breastfeeding's health benefits for mother and baby (Figure 1) with a mean total score of 12.2 points out of 16 . In addition, they were aware that breastfeeding gives the baby all the needed nutrients during the first 6 months, needs no preparation and protects the mother against breast cancer (represented as 92\%, 75\% \& 53\% respectively) (Table 4). Thus, participants were aware with the major breastfeeding benefits that may encourage them to practice it.

Regarding the participants' breastfeeding perceived barriers, the most commonly reported barriers were lack of knowledge (71\%), returning to work or school and using contraception (69\%) (Table 5). These barriers can be minimised by increasing a mothers' knowledge and adapting work policies.

Table 3. Distribution of the Participants by their Breastfeeding Education during the Current Pregnancy

\begin{tabular}{|l|c|}
\hline \multicolumn{1}{|c|}{ Item } & Percent $(\mathbf{n = 1 0 0})$ \\
\hline Had breastfeeding education & 56 \\
$\bullet$ Yes & 44 \\
- No & \\
\hline When & 33 \\
- During antenatal follow up & 23 \\
- Postnatal & \\
\hline By whom & 28 \\
- Nurse & 18 \\
- Doctor & 10 \\
- Locational specialist & \\
\hline
\end{tabular}

Table 4. Distribution of the Participants by their Knowledge about Benefits of Breastfeeding

\begin{tabular}{|l|c|c|c|}
\hline \multicolumn{1}{|c|}{ Item } & Yes & Uncertain & No \\
\hline $\begin{array}{l}\text { Breastfeeding gives the baby all the needed nutrients during the } \\
\text { first 6 months (True). }\end{array}$ & 92 & 8 & 0 \\
\hline $\begin{array}{l}\text { Breastfed babies have less diarrhoea than formula fed babies } \\
\text { (True). }\end{array}$ & 75 & 20 & 5 \\
\hline $\begin{array}{l}\text { Breastfed babies develop fewer diseases during childhood than } \\
\text { formula fed babies (True). }\end{array}$ & 74 & 20 & 6 \\
\hline $\begin{array}{l}\text { Bottle fed babies are more intelligent than breastfed babies } \\
\text { (False). }\end{array}$ & 31 & 23 & 46 \\
\hline $\begin{array}{l}\text { Breastfeeding does not protect the mother against breast cancer } \\
\text { (False). }\end{array}$ & 24 & 23 & 53 \\
\hline $\begin{array}{l}\text { Breastfeeding does not protect the mother against postpartum } \\
\text { haemorrhage (False). }\end{array}$ & 25 & 37 & 38 \\
\hline Breastfeeding helps mothers to loose weight (True). & 65 & 12 & 23 \\
\hline Breast milk needs no preparation (True). & 75 & 9 & 16 \\
\hline
\end{tabular}


Table 5. Distribution of the Participants by their Breastfeeding Perceived Barriers

\begin{tabular}{|l|c|c|c|}
\hline \multicolumn{1}{|c|}{ Item } & Agree & Uncertain & Disagree \\
\hline Returning to work or school & 69 & 4 & 27 \\
\hline Fear of losing breasts shape and size & 51 & 12 & 37 \\
\hline Tiredness and fatigue after delivery & 64 & 6 & 30 \\
\hline Insufficient milk supply & 68 & 14 & 18 \\
\hline Difficulty with baby feeding & 62 & 13 & 25 \\
\hline Advertisement about newly developed formulas & 45 & 15 & 40 \\
\hline Availability of formula milk & 46 & 12 & 42 \\
\hline $\begin{array}{l}\text { Negative family attitude (e.g. conflict over the gender } \\
\text { of baby) }\end{array}$ & 26 & 22 & 52 \\
\hline Fear of pain & 53 & 13 & 34 \\
\hline Embracement from nursing in public & 58 & 21 & 21 \\
\hline Housekeeper availability & 46 & 12 & 42 \\
\hline Lack of knowledge & 71 & 11 & 18 \\
\hline Lack of support from husband/family/doctor/nurse & 58 & 14 & 28 \\
\hline Being too busy & 65 & 11 & 24 \\
\hline Using contraception & 69 & 10 & 21 \\
\hline
\end{tabular}

Figure 1. Participants' Knowledge Level about Benefits of Breastfeeding

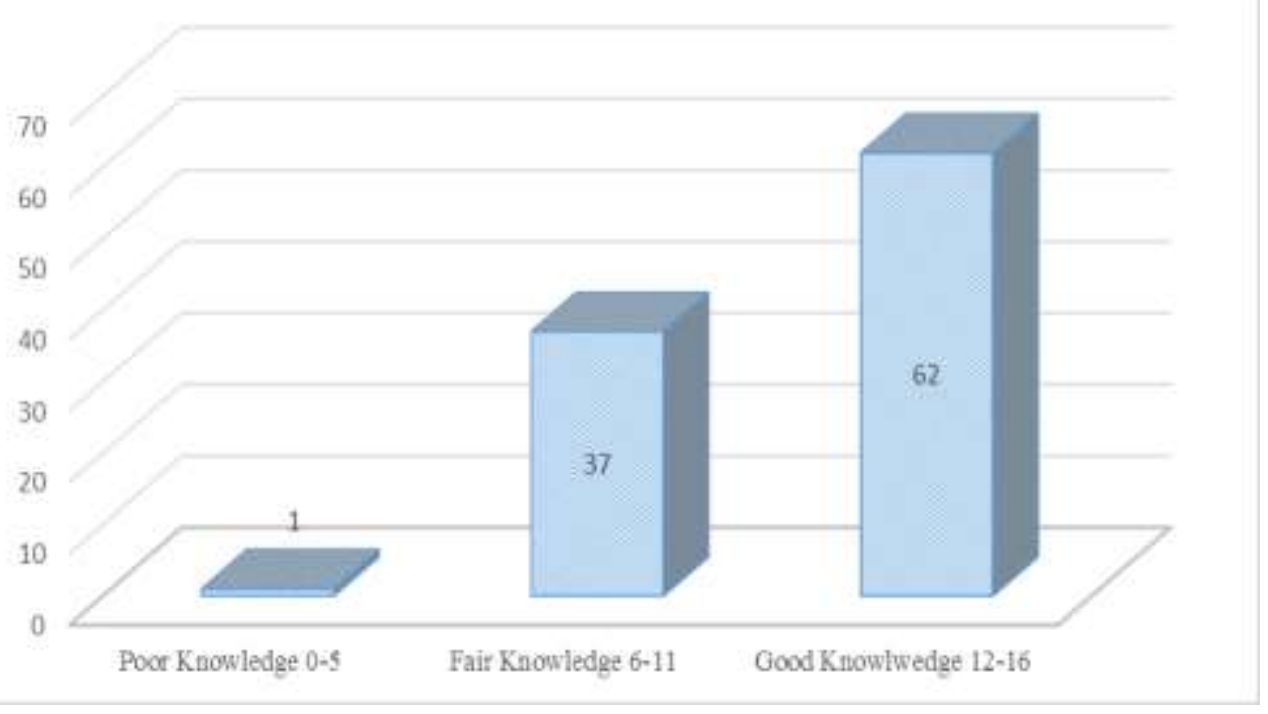

In relation to the participants' attitudes toward the breastfeeding, minority of them $(10 \%)$ had a positive attitude toward breastfeeding (Figure 2) with a mean total score of 58.2 points out of 85 .

Concerning breastfeeding practice in previous delivery, only $(9 \%)$ of the participants exclusively breastfed their babies during the first six months of life (Figure 3). The mean duration of each breastfeeding episode in minutes was (8.5 \pm 8.9$)$. Additionally, the mean duration of breastfeeding in months was $(3.1 \pm 4.4)$. In relation to breastfeeding practice in present delivery, half of the participants $(53 \%)$ had skin to skin contact after delivery. However, the minority of them (18\%) initiated breastfeeding within one hour after delivery 
(Figure 4). Causes for delayed breastfeeding initiation were maternal pain or fatigue and neonatal sleeping (represented as $30 \%, 12 \%$ \& $2 \%$ respectively). Nearly all the participants $(95 \%)$ gave supplemental feeding in the hospital (Figure 5) and only (18\%) decided to breastfeed their babies exclusively after discharge (Figure 6).

Figure 2. Participants' Attitudes Toward Breastfeeding

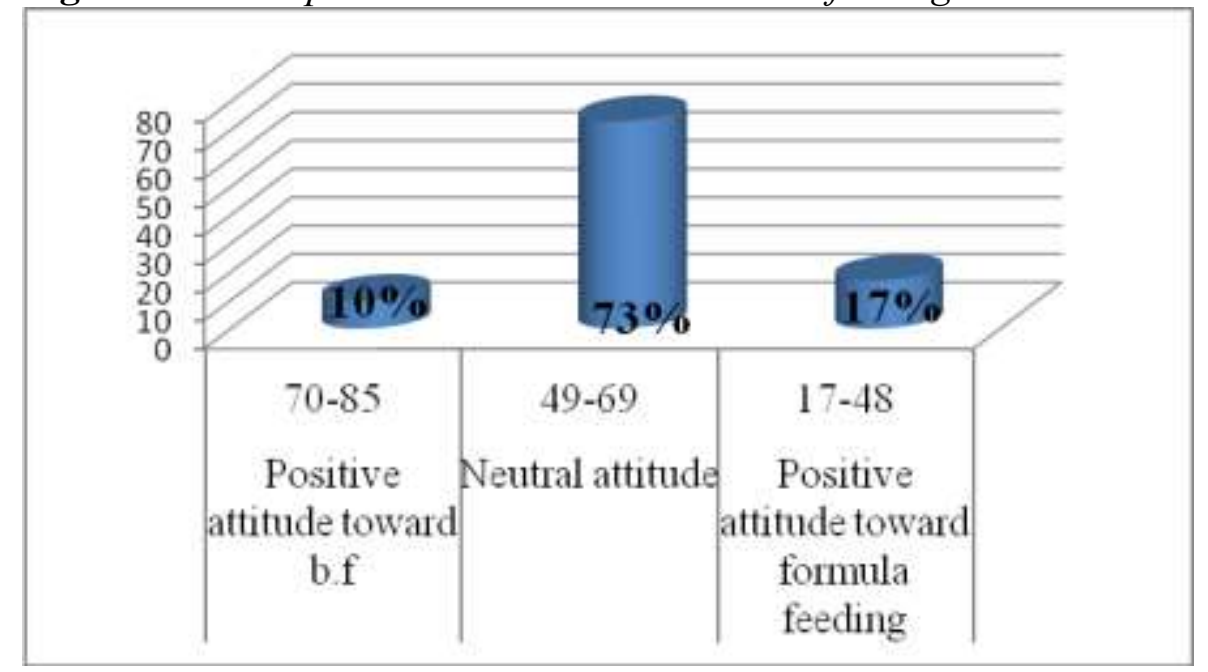

Figure 3. Method of Infant Feeding in the First 6 Months of Life

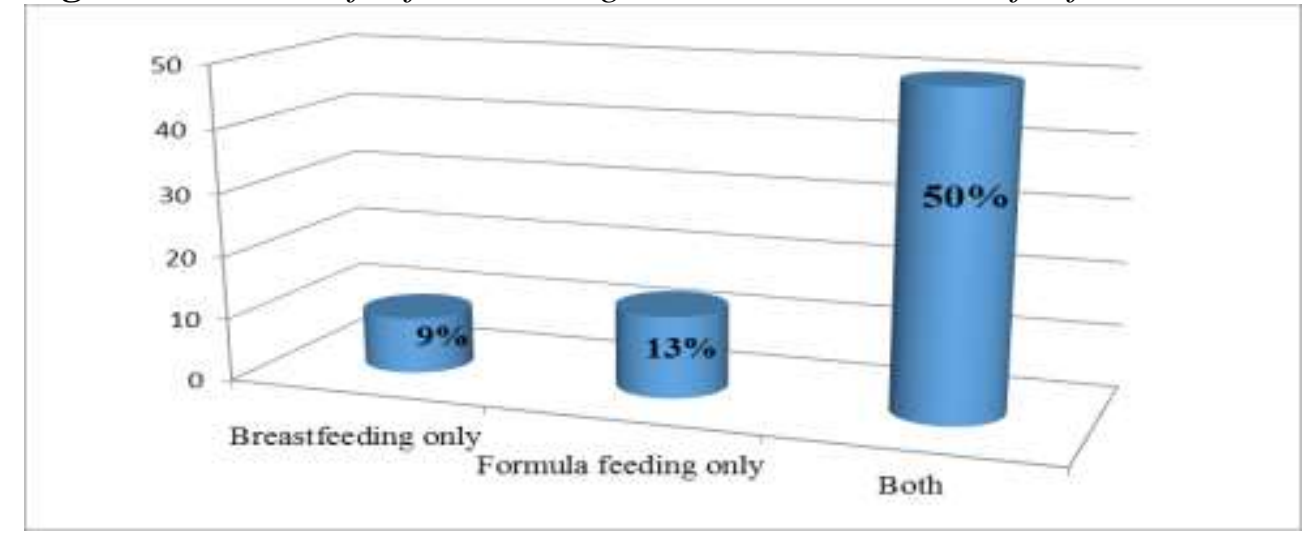

Figure 4. Initiation of Feeding after Delivery in the Present Delivery 


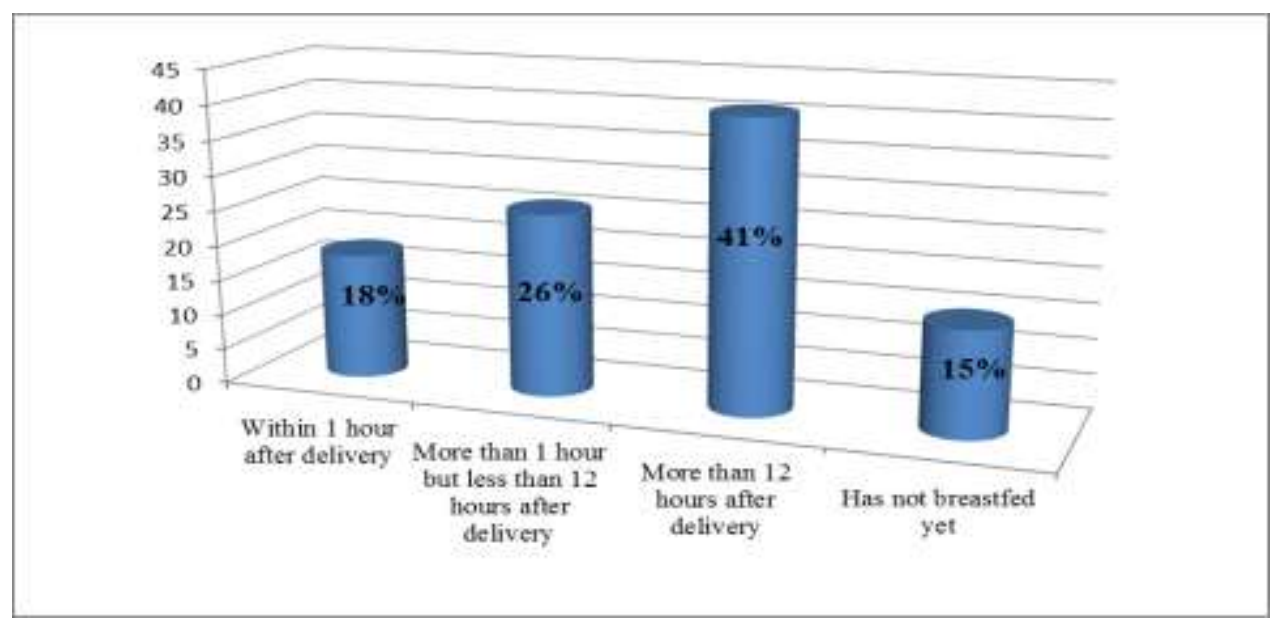


Figure 5. Supplemental Feeding in the Hospital

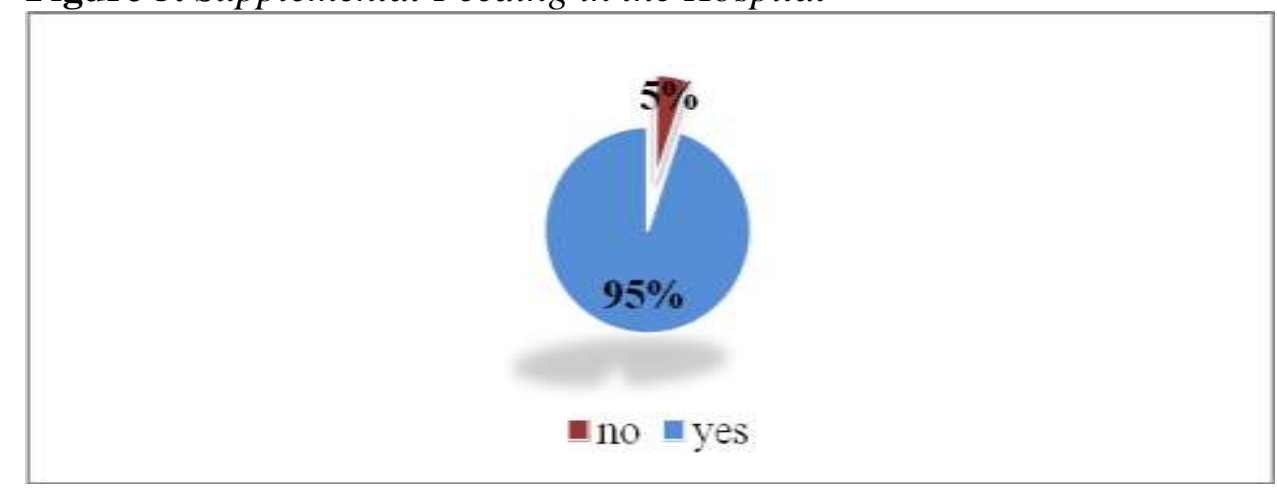

Figure 6. Feeding Method at Discharge

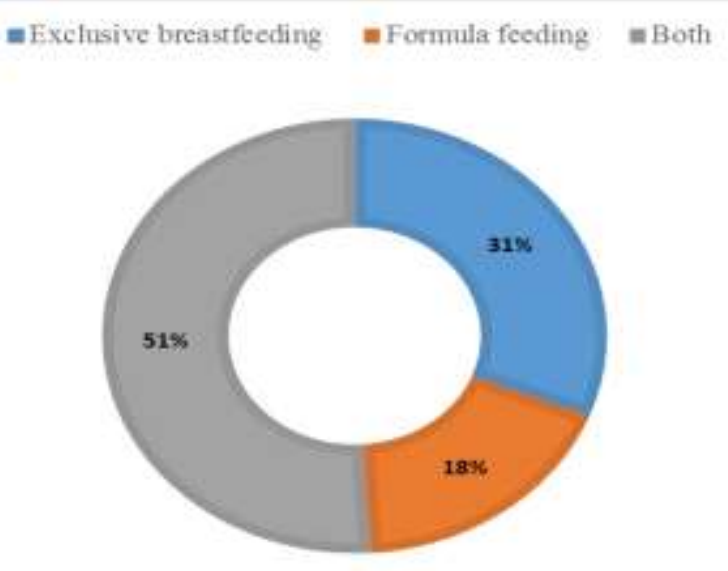

Considering the relationship between breastfeeding knowledge, breastfeeding attitudes and the socio-demographic background of the participants, statistically significant correlations were found between breastfeeding knowledge and maternal age and breastfeeding duration $(\mathrm{r}=0.22)$, also there was a good significant correlation between women's knowledge level and their attitude toward breastfeeding $(\mathrm{r}=0.50)$ (Table 6). This indicates that older participants have better knowledge and longer breastfeeding duration. Additionally, participants who have better knowledge have more positive attitude toward breastfeeding. Regarding the relationship between breastfeeding perceived barriers and the socio-demographic background of the participants, statistical significant relationships were found between returning to work or school, insuffient milk supply negative family attitude and housekeeper availability and participants' educational level $(\mathrm{p}=0.01, \mathrm{p}=0.007$, $\mathrm{p}=0.007 \& \mathrm{p}=0.03$ respectively). Also, a statistical significant relationship was found between employment and returning to work $(\mathrm{p}=0.04)$ (Table 7).

Table 6. Relationship Between Breastfeeding Knowledge, Attitudes and SocioDemographic Back Ground of the Participants

\begin{tabular}{|l|c|c|c|c|}
\hline Item & \multicolumn{2}{|c|}{ Knowledge } & \multicolumn{2}{c|}{ Attitudes } \\
\hline & $\boldsymbol{r}$ & $\boldsymbol{p}$-value & $\boldsymbol{r}$ & $\boldsymbol{p}$-value \\
\hline Age & $0.22^{*}$ & 0.03 & 0.04 & 0.67 \\
\hline
\end{tabular}




\begin{tabular}{|l|c|c|c|c|}
\hline Number of children & 0.05 & 0.61 & 0.01 & 0.89 \\
\hline Knowledge & 1 & & $0.50^{*}$ & 0.0001 \\
\hline Breastfeeding duration & $0.22^{*}$ & 0.03 & 0.05 & 0.62 \\
\hline
\end{tabular}

Table 7. Relationship Between Breastfeeding Perceived Barriers and SocioDemographic Background of the Participants

\begin{tabular}{|l|c|c|}
\hline Item & Educational & Employment \\
\hline Returning to work & $\mathrm{p}=0.01^{*}$ & $\mathrm{p}=0.04^{*}$ \\
\hline Insuffient milk supply & $\mathrm{p}=0.007^{*}$ & \\
\hline Negative family attitude & $\mathrm{p}=0.007^{*}$ & \\
\hline House keeper availability & $\mathrm{p}=0.03^{*}$ & \\
\hline
\end{tabular}

Regarding the description of the participants who had a good knowledge score, $(68 \%)$ of them were multiparous, $(82 \%)$ of them were highly educated, (94\%) of them had less than 5 children, (89\%) of them had antenatal follow up during current pregnancy and (57\%) of them had an unplanned pregnancy. Similarly, (90\%) of the participants who had positive attitude score were highly educated, (80\%) of them had less than 5 children, (100\%) of them had an antenatal follow up during current pregnancy and (60\%) of them had an unplanned pregnancy. In contrast, the majority of them (70\%) were primiparous.

\section{Discussion}

The current study aimed at investigating the knowledge, attitudes, practices and perceived barriers of breastfeeding among Saudi women in the National Guard Hospital Jeddah. Findings of the current study revealed that, however two thirds of the mothers have good knowledge about some of the breastfeeding benefits. A high percent of them have neutral attitudes toward it. The reason for being aware that breastfeeding benefits might be related to the high educational level of the majority of them as well as breastfeeding education of more than half of them.

The breastfeeding barrier can impede mothers from its practice. In the current study, lack of knowledge, returning to work or school, using contraception and insufficient milk supply were the most commonly identified among study participants. In the same context, Hala et al. (2013) conducted a study in Riyad and found the same findings regarding breastfeeding knowledge and attitude toward it. But, embarrassment from lactation in public places and working were the common identified barriers by the women (represented as $83.2 \% \& 73.5 \%$ ) (Hala et al. 2013). The same conclusion had been reached by Alfaleh who found that, $(41 \%)$ of the participants attended breastfeeding awareness programs but, diffusing artificial milk, duration of vacation after delivery and deficient knowledge were the barriers for breastfeeding (Alfaleh 2014).

Regarding breastfeeding practice in previous delivery, less than one tenth of the participants exclusively breastfed their babies in the first six months with a mean duration of three months. Concerning breastfeeding practice in present delivery, less than one quarter of them had initiated breastfeeding within the first hour after delivery although, more than half of them had erected nipple. Reasons for delaying breastfeeding initiation were fatigue or pain of most of the participants. An explanation of these findings may be the neutral attitude of 
majority of the participants toward breastfeeding, as favorable attitudes are necessary to initiate and maintain breastfeeding practice. These results are highlighted on a previous national research which revealed a lowered percent of breastfeeding practice in spite of being highly educated as well as non-exclusive feeding was the common way of feeding (Alwelaie et al. 2010). In contrast, a study conducted in Al-Hassa revealed that, breastfeeding was started by (77.8\%) of women within the first 24 hours after delivery. Additionally $76.1 \%$ of women breastfed their babies exclusively but this percent decreased to $32.9 \%$ and $12.2 \%$ at the second and sixth month, respectively (El-Gilany et al. 2012).

Findings of the current study revealed a positive correlation between mother's age and breastfeeding knowledge and breastfeeding duration, also a good significant correlation between the level of knowledge and the attitude toward breastfeeding. These results are comparable to results of Hala et al. (2013). Unsurprisingly, employment was significantly related to returning to work as a barrier of breastfeeding practice.

Surprisingly, the majority of the participants who had a positive attitude toward breastfeeding were primiparous. Thus, previous experience had a reverse impact on the attitudes toward breastfeeding. This contradiction may be clarified as multiparous women may face some breastfeeding problems during previous delivery that made them less enthusiastic to breastfeed their babies. At the same context, having an unplanned pregnancy was not from the main factors affecting breastfeeding knowledge and attitude as it was accompanied with positive breastfeeding attitude and a good knowledge level. As expected, being highly educated and having antenatal care are accompanied with positive breastfeeding attitude and good knowledge level, which highlight the importance of antenatal follow up and health education during every pregnancy either at a low or high risk.

\section{Conclusion}

Based on study findings, it can be concluded that:

- Study participants have a good knowledge regarding breastfeeding's health benefits for mother and baby.

- Participants have a neutral attitude toward breastfeeding.

- Participant's knowledge level is positively correlated with their age and attitude toward breastfeeding.

- Several barriers might prevent participants from breast feeding their babies although they have good knowledge regarding its importance.

- A statistically significant relation was found between the most common identified breastfeeding barriers and educational level.

- Not all participants had been educated regarding breastfeeding.

\section{Recommendations}

The followings strategies are recommended to promote and encourage breastfeeding as well as improve the rates of exclusive breastfeeding: 
- Mothers need to be supported from family to practice breastfeeding.

- Importance of antenatal follow up should be emphasized.

- Health education about importance of breastfeeding should be part of antenatal care and nursing management to increase its perceived value.

- Postnatal follow up of mothers to assure their breastfeeding practice and trying to solve any faced problem or overcome barriers.

\section{References}

AAP - American Academy of Pediatrics (2012) Breastfeeding and the use of human milk. Pediatrics 129(3): 600-603.

Alfaleh KM (2014) Perception and knowledge of breast feeding among females in Saudi Arabia. Journal of Taibah University Medical Sciences 9(2): 139-142.

Al-Juaid DA, Binns CW, Giglia RC (2014) Breastfeeding Saudi Arabia: a review. International Breastfeeding Journal 9(1): 1746-1186.

Alwelaie YA, Alsubaibani EA, Al-Harthy AM, Radwa RH, Al-Mobammady RG, AlMutairi AM (2010) Breastfeeding knowledge and attitudes among Saudi women in central Saudi Arabia. Saudi Medical Journal 31(2): 193-198.

Amitay EL, Boker LK (2015) Breastfeeding and childhood leukemia incidence: a meta-analysis and systematic review. JAMA Pediatrics 169(6):515-612 .

Black RE, Victora CG, Walker SP, Bhutta ZA, Christian P, De Onis M et al. (2013) The maternal and child under-nutrition and over-weight in low-income and middle-income countries. Lancet 382(9890): 427-451.

Cara L, Echhardt TL, Njeri KG (2014) Knowledge, attitudes and beliefs that can influence infant feeding practices in American Indian mothers. Journal of the Academy of Nutrition and Dietetics 114(10): 1587-1593.

Chapman DJ (2012) Longer Cumulative breastfeeding duration associated with improved bone strength. Journal of Human Lactation 28(1):18-19.

Collaborative Group on Hormonal Factors in Breast Cancer (2002) Breast cancer and breastfeeding: collaborative reanalysis of individual data from 47 epidemiological studies in 30 countries, including 50302 women with breast cancer and 96973 women without the disease. Lancet 360(9328): 187-195.

Debes AK, Kohli A,Walker N, Edmond K, Mullany LC (2013) Initiation of breastfeeding and neonatal mortality and morbidity. BMC Public Health 13(Suppl. 3): S19.

De La Mora A, Russel DW, Dungy CI, Losch M, Dushieker L (1999) The Iowa Infant Feeding Attitude Scale (IIFAS): analysis of reliability and validity. Journal of Applied Social Psychology 29(11): 2362-2380.

Dungy CL, Mclnnes RJ, Tappin DM, Wallis AB (2008) infant feeding attitude and knowledge among socioeconomically disadvantaged women in Glasgow. Maternal Child Health Journal 12(3): 313-322.

Dungy CL, Losch ME, Russell DW (1994) Maternal attitudes as predictors of infant feeding decisions. Journal of the Association for Academic Minority Physicians 5(4): 159-164.

El Mouzan MI, Al Omar AA, Al Salloum AA, Al Herbish AS, Ourachi MM (2009) Trends in infant nutrition in Saudi Arabia: compliance with WHO recommendations. Annals of Saudi Medicine 29(1): 20-23.

El-Gilany AH, Sarraf B, Al-Wehady A (2012) Factors associated with timely initiation of breastfeeding in Al-Hassa Provonce, Saudi Arabia. Eastern Mediterranean Health Journal 18(3): 250-4. 
Furman LM, Banks EC, North AB (2013) Breastfeeding among high-risk inner city African American mothers: a risky choice?. Breastfeeding Medicine 8(1): 58-67.

Hala S, Afaf M, Afnan S, Wadaa A (2013) Breastfeeding knowledge, attitudes and barriers among Saudi Women in Riyadh. Journal of Natural Sciences Research 3(12): 6-13.

Horta BL, Victoram CG (2013) Long-term effects of breastfeeding: a systematic review. Geneva: World Health Organization Retrieved from goo.gl/Sxi9mC. [Accessed: 7 October 2014]

Kramer MS, Kukuma R (2012) Optimal duration of exclusive breastfeeding. Cochrane Database Systematic Review 15(8): CD003517.

Labbok M (2001) Effects of Breastfeeding on the Mother's Pediatric Clinic North America. W. B. Saunders Company 48(1).

Mosalli R, Abd El-Azim A, Qutub M, Zagoot E, Janish M, Paes B (2012) Perceived barriers to the implementation of a baby friendly initiative in Jeddah, Saudi Arabia. Saudi Medical Journal 33(8): 895-900.

Nagata C, Mizoue T, Tanaka K, Tsuji I, Tamakoshi A, Wakai K et al. (2012) Breastfeeding and breast cancer risk: an elevation based on a systematic review of epidemiologic evidence among the Japanses population. Japanese Journal of Clinical Oncology 42(2): 124-130.

Oddy WH, Zubrick SR, Malacova E (2011) Breastfeeding duration and achievement at 10 years. Pediatrics 127(1): E137-E145.

Rani M (2014, April 14) 5 reasons American women won't breastfeed. The Wall Street Journal. Retrieved from goo.gl/6CEbsC.

Sobhy SI (2004) Egypt Public Health Association. Retrieved from goo.gl/33IiW0.

Scott JA, Binns CW, Graham KL, Oddy WH (2006) Temporal changes in determinants of breastfeeding initiation. Birth 33(1): 37-45.

Whalen B, Cramton R (2012) Overcoming barriers to breastfeeding: continuation and exclusivity. Current Opinion in Pediatrics 22(5): 655-663. 
